\title{
Plant Density Influences Marketable Yield of Directly Seeded 'Piquillo' Pimiento Pepper
}

\author{
R. Gil Ortega and M. Gutierrez \\ Servicio de Investigación Agroalimentaria, Apdo. 727, 50080 Zaragoza, \\ Spain
}

\author{
J. Cavero ${ }^{1}$ \\ Departamento de Genética y Producción Vegetal, Estación Experimental de \\ Aula Dei (CSIC), Apdo. 202, 50080 Zaragoza, Spain
}

Additional index words. Capsicum annuum, radiation interception, canning pepper

\begin{abstract}
Pimiento pepper (Capsicum annuum var. annuum L. 'Piquillo') was directly seeded on raised beds in double rows $0.35 \mathrm{~cm}$ apart. Plants were thinned within the row to establish densities ranging from 13,333 to 186,667 plants/ha. Marketable yield of pepper increased as plant density increased to 100,000 plants/ha. However, with plant densities $>100,000$ plants/ha, marketable yield did not increase (2001) or slightly decreased (2000). Plant density affected pepper yield only in the first harvest date. Fruit number and fruit weight per plant decreased with increasing plant populations. Weight per fruit decreased slightly at densities $>100,000$ plants/ha. The increase in yield per hectare as plant density increased was mainly a result of increased number of fruit per hectare. The intercepted PAR by the pepper canopy increased with increases in plant density to about 100,000 plants/ha and this increased interception of PAR resulted in an increase in yield. Plant densities in the range of 100,000 to 120,000 plants/ha were optimal in terms of marketable yield.
\end{abstract}

Studies on plant populations for peppers (Batal and Smittle, 1981; Cavero et al., 2001; Decoteau and Graham, 1994; Jolliffe and Gaye, 1995; Locascio and Stall, 1994; Motsenbocker, 1996; Stoffella and Bryan, 1988; Sundstrom et al., 1984) do not agree on an optimum plant density because this is influenced by many factors. These are the growing system, including the method of establishment (transplanting or direct seeding), the distance between rows and the in-row plant spacing, as well as other factors, such as fertility or cultivar traits.

Plant biomass production per area of land is directly related to solar radiation interception (Loomis and Connor, 1992). Solar radiation interception depends on leaf area index, which is strongly determined by plant density and arrangement. Thus, Cebula (1995) and Lorenzo and Castilla (1995) reported higher radiation interception because of higher leaf area index at higher plant densities, which resulted in higher biomass and pepper fruit yield.

Usually, a linear increase in fruit yield as plant density increased has been found (Decoteau and Graham, 1994; Jolliffe and Gaye, 1995; Motsenbocker, 1996; Stoffella and Bryan, 1988). Limitations of transplanting equipment have precluded testing high densities. However, this is not a limitation with direct seeding. Cavero et al. (2001) studied high densities in direct-seeded paprika pepper and found an asymptotic relationship between yield and plant density. Nevertheless, Stoffella and

Received for publication 22 Sept. 2003. Accepted for publication 5 Apr. 2004. This work was funded by the MICYT (project 2FD97-0517).

${ }^{1}$ To whom reprint requests should be addressed; e-mail jcavero@eead.csic.es.
Bryan (1988) using plug-mix seeding found a linear increase of marketable fruit of bell pepper in response to high plant populations.

Direct seeding allows increase of plant densities easily without a significant increase in costs for labor and planting. The higher costs associated with increases in plant density are primarily due to the increased number of seeds used. However, plant density could affect pepper value because fruit quality as determined by fruit size and color could be altered. Most authors reported that peppers per hectare as plant density increased, whereas fruit size was unaffected (Stoffella and Bryan, 1988). If peppers are mechanically harvested, fruit size can affect the different processes involved, and if hand-harvested, smaller fruit will increase costs.

The objective of this research was to study how plant density of directly seeded 'Piquillo' pimiento pepper affects yield, yield components and fruit quality.

\section{Materials and Methods}

Field experiments were conducted during 2000 and 2001 at the Ejea Experimental Farm (Zaragoza, Spain). The soil is Petrocalcic Calcixerept with a silty clay loam texture $(41.5 \%$ sand, $43.5 \%$ silt, $15.0 \%$ clay), $4.3 \%$ organic matter and a $\mathrm{pH}$ of 8.2. Fertilization consisted of a broadcast, preplant-incorporated applicaon Mar. in both years and one top dressing on June of $15 \mathrm{~N}-2.2 \mathrm{P}-16.6 \mathrm{~K}-1.2 \mathrm{Mg}$ at $470 \mathrm{~kg} \cdot \mathrm{ha}^{-1}$ in 2000 and with ammonium nitrate $(33.5 \% \mathrm{~N})$ at $300 \mathrm{~kg} \cdot \mathrm{ha}^{-1}$ in 2001.

Seed of 'Piquillo', the main Spanish piproduced fewer fruit per plant but more fruit tion of $12 \mathrm{~N}-5.2 \mathrm{P}-14.1 \mathrm{~K}-1.2 \mathrm{Mg}$ at $350 \mathrm{~kg} \cdot \mathrm{ha}^{-1}$ miento pepper cultivar for canning, was used for direct seeding each year. The seed was produced at the Ejea Experimental Farm. Seeds were treated with tetramethylthiuram disulfide (thiram) at $5 \mathrm{~g} \cdot \mathrm{kg}^{-1}$ before planting, and planted on raised beds on 31 Mar. 2000 and 4 Apr. 2001. Beds were $1 \mathrm{~m}$ wide and $20 \mathrm{~cm}$ high, with $1.5 \mathrm{~m}$ between the centers of contiguous beds. Two rows ( $0.35 \mathrm{~m}$ apart $)$ were seeded on each bed as described by Cavero et al. (1996). Seeding was performed with a commercial pneumatic seed drill (model SV260; Gaspardo, Pordemone, Italy) modified as described by Cavero et al. (1996) at a distance between seeds of $3.8 \mathrm{~cm}$. Clear polyethylene mulch (Castillo Arnedo, Calahorra, Rioja, Spain), $25 \mu$ m thick and $1.2 \mathrm{~m}$ wide, was mechanically placed on the bed using a plastic layer (Gadea, Tauste, Zaragoza, Spain). The plot was irrigated immediately after seeding.

When daily maximum soil temperature under the polyethylene mulch was consistently higher than $35^{\circ} \mathrm{C}$, the film was perforated manually (one hole $3 \mathrm{~cm}$ in diameter every $0.25 \mathrm{~m}$ along the bed). The plastic was removed when the plants had two to three true leaves (10 May 2000, 16 May 2001).

Plants were hand-thinned to the desired inrow spacing on 12 June 2000 and on 7 June 2001 (plants had 6 to 8 leaves). Plant densities in 2000 were $13,333,40,000,66,666,93,333,120,000$, 146,667 , and 173,333 plants/ha, and in 2001 densities were 13,333, 26,666, 40,000, 53,333, $66,666,93,333,120,000,146,667,173,333$ and 186,667 plants/ha. The experimental plot unit consisted of one 3-m-long raised bed with two rows per bed. The experimental design was completely randomized with four replicates for each density.

Weeds were controlled with $N, N$-diethyl-2-(1-naphthalenyloxy)propanamide (napropamide) at $2.03 \mathrm{~kg} \cdot \mathrm{ha}^{-1}$ and $2-[(2-$ chlorophenyl)methyl]-4,4-dimethyl-3-isoxazolidone (clomazone) at $0.36 \mathrm{~kg} \cdot \mathrm{ha}^{-1}$ applied after sowing, and with mechanical cultivation and manual hoeing after removal of the polyethylene mulch. Furrow irrigation was used to irrigate the plots every 7 to $14 \mathrm{~d}$. Irrigation was stopped on 15 Sept.

Marketable red fruit were harvested twice every year (23 Sept. and 28 Oct. 2000, 30 Aug. and 28 Sept. 2001) from the central 1-m section of each plot. Plants were counted in this section. Fruit were weighed in the field. One sample of 10 fruit per plot was weighed to determine fruit weight. These fruit were used for color determination on each of the 10 clean, intact fruit surfaces by a photoelectric tristimulus colorimeter (CR-200; Minolta, Osaka, Japan) working in the CIELAB color space $\left(L^{*}, a^{*}, b^{*}\right)$. The values obtained were used to calculate the chromatic attribute "hue angle" (b*/a*) (Mc Guire, 1992).

In 2001, the photosynthetically active radiation (PAR) intercepted by the crop was measured every one or two weeks with a 0.8-mlong Accupar ceptometer (Decagon Devices, Pullman, Wash.) beginning on 20 June. The fraction of PAR intercepted in each plot was calculated by rapidly taking four measurements above the canopy, four below the canopy, and 

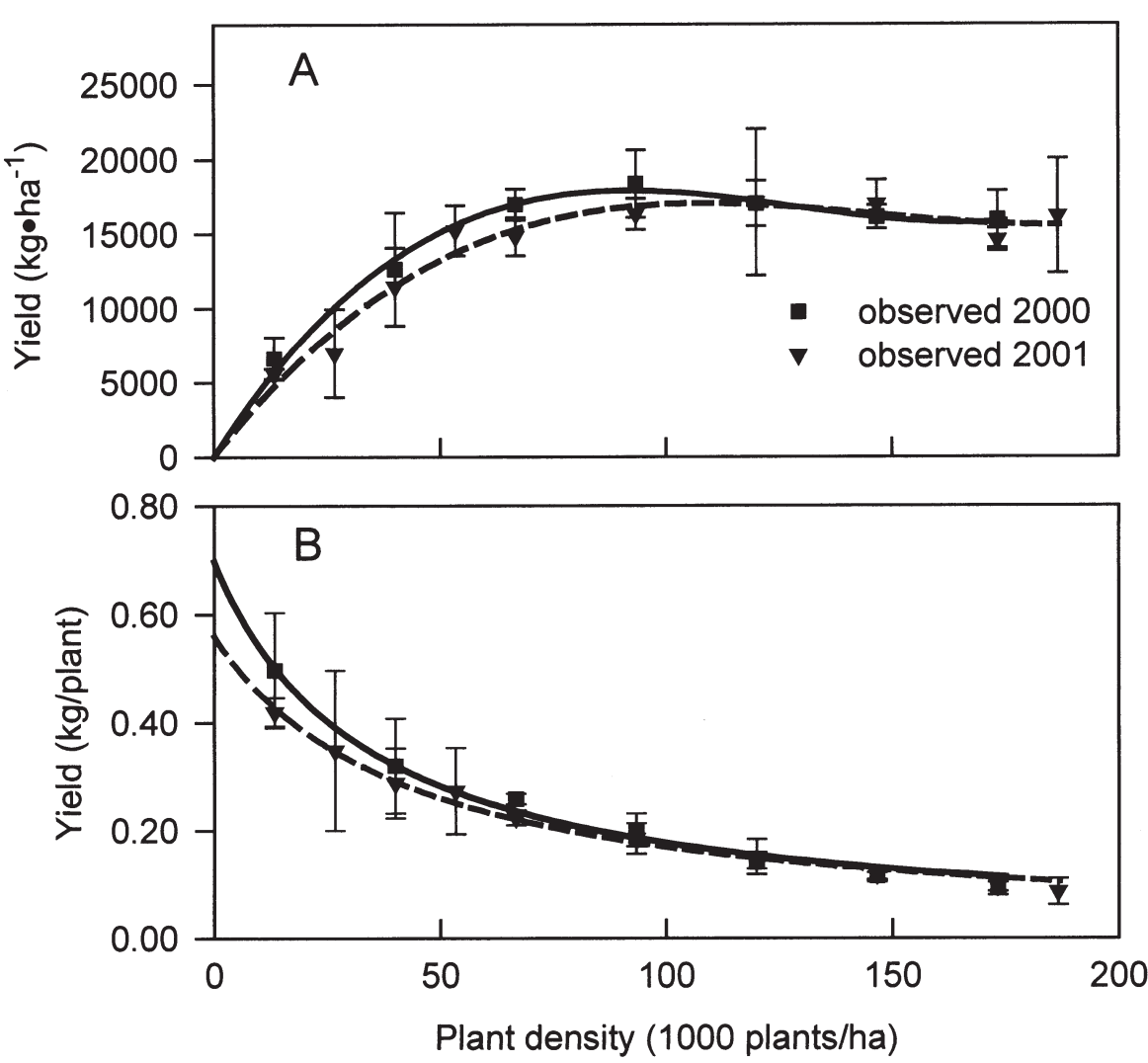

four more above the canopy around noon. The mean of each set of four readings was recorded. The above and below canopy readings were taken with the ceptometer placed perpendicularly to the plant rows and centered in the bed. Thus, the percentage of intercepted PAR was calculated considering that the ceptometer was
$0.8 \mathrm{~m}$ long and that the distance between center of beds was $1.5 \mathrm{~m}$. Daily estimates of fraction PAR intercepted by the pepper canopy were obtained by linearly interpolating between measurement dates. Daily values for incoming PAR were calculated from values of total solar radiation measured in a weather station near

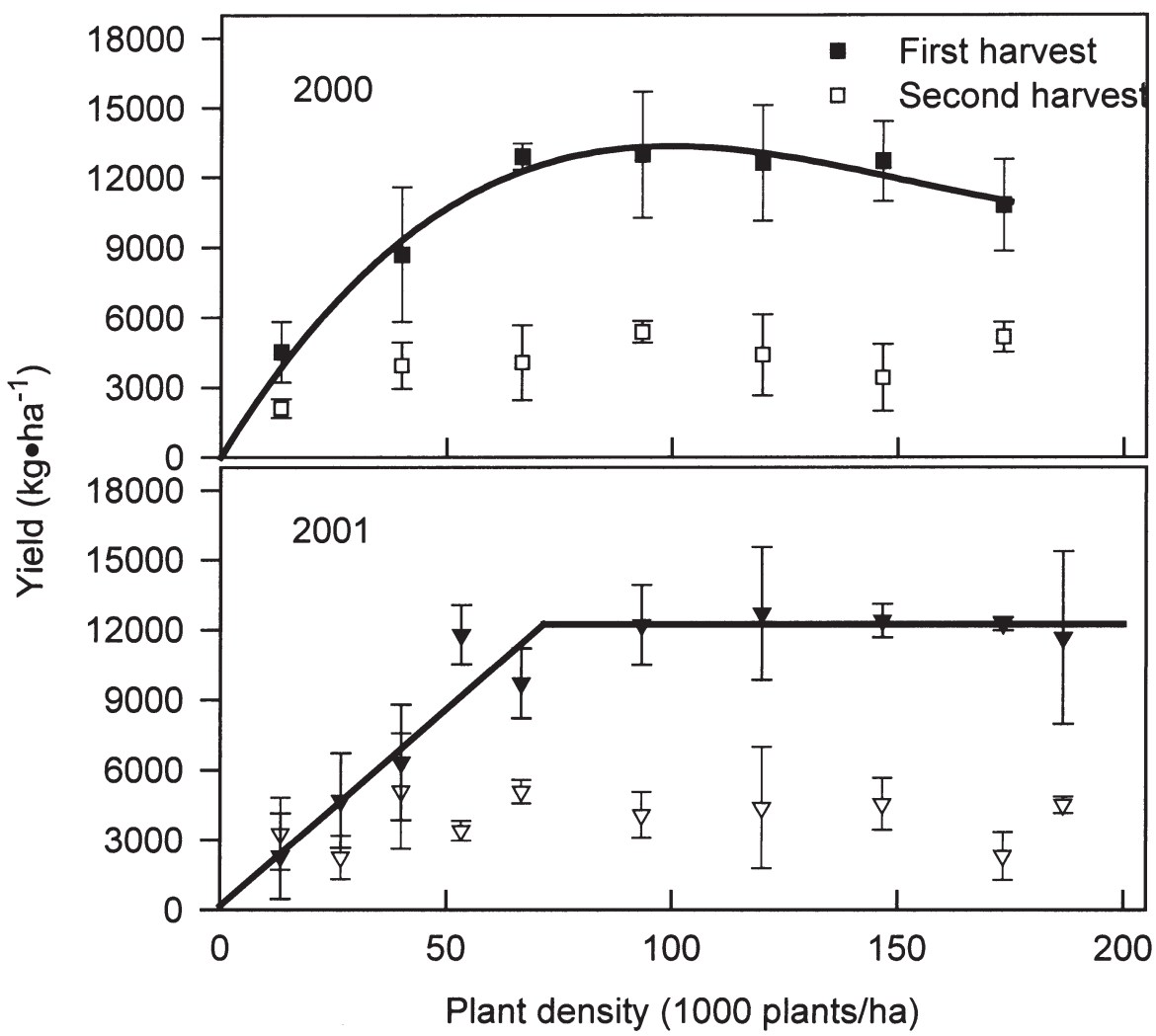

Fig. 1. Plant density effect on marketable yield per hectare (A) and per plant of pimiento pepper (B) in 2000 and 2001. The lines are regression curves for 2000 (solid line) and 2001 (dashed line). Error bars represent \pm 1 standard deviation. For the yield per hectare, $\boldsymbol{y}=a \boldsymbol{x}+b \boldsymbol{x}^{2}+c \boldsymbol{x}^{3}$. In 2000, $a=0.478(P<0.001), b=-4.05 \times 10^{-6}(P$ $<0.001), c=1.05 \times 10^{-11}(P<0.001), r^{2}=0.99$. In 2001, $a=0.392(P<0.001), b=-2.86 \times 10^{-6}$ $(P<0.001), c=6.56 \times 10^{-12}(P<0.01), r^{2}=0.99$. The regression curve for the yield per plant is $y$ $=a /[1+(a x / b)]$. In 2000, $a=0.697 \pm 0.043, b$ $=23,730 \pm 1,671, r^{2}=0.99$. In 2001, $a=0.559$ $\pm 0.025, b=24,140 \pm 1,339, r^{2}=0.99$.

the site by assuming that $45 \%$ of the total solar radiation was PAR (Meek et al., 1984).

Data were analyzed by regression analysis, either linear or non-linear, with STATGRAPHICS (1988). Regression analysis was done for each year's data.

\section{Results}

Marketable yield per hectare and per plant. Marketable yield per hectare increased as plant density increased to about 90,000 plants/ha in 2000 and 110,000 plants/ha in 2001 (Fig. 1). Marketable yield slightly decreased with further increases in plant density. This decrease was more important in 2000 (Fig. 1).

In both years, marketable yield per plant decreased asymptotically as plant density increased (Fig. 1).

In both years, plant density affected pepper yield only in the first harvest date (Fig. 2). At that harvest, yield increased as plant density increased to about 67,000 plants/ha in 2000 , slightly decreasing with further increases in plant density. In 2001, the regression that better explained the relationship between plant density and marketable yield at the first harvest was the linear-plateau (Cerrato and Blackmer, 1990). Yield increased linearly as plant density increased until 72,000 plants/ha and remained stable at higher plant densities (Fig. 2).

Yield components. Both years, the number of fruit per plant decreased asymptotically as plant density increased (Fig. 3A), particularly at densities $<50,000$ plants/ha.

In 2000 , the average fruit weight slightly decreased as plant density increased above 100,000 plants/ha (Fig. 3B), but the regression was significant $(P<0.05)$. In 2001 , the average fruit weight increased as plant density increased until 120,000 plants/ha and slightly decreased at plant densities higher than 150,000 plants/ha.

The relationship between the number of fruit per hectare and plant density was a lin-

Fig. 2. Plant density effect on marketable yield of pimiento pepper at the two harvest dates in 2000 (A) and 2001 (B). The lines are regression curves and error bars represent \pm 1 standard deviation. For the first harvest date in 2000, $y$ $=a \boldsymbol{x}+b \boldsymbol{x}^{2}+c \boldsymbol{x}^{3}$ with $a=0.320(P<0.001)$, $b=-2.40 \times 10^{-6}(P<0.01), c=5.29 \times 10^{-12}(P$ $<0.05), r^{2}=0.99$. For the first harvest date in 2001, the linear plateau equation was used, $\boldsymbol{y}=$ $a+b \boldsymbol{x}$ if $\boldsymbol{x}<c$ and $\boldsymbol{y}=a+b c$ if $\boldsymbol{x} \geq c$, with $a$ $=189.2 \pm 839.7, b=0.169 \pm 0.021, c=71,528$ $\pm 6290, r^{2}=0.95$. 

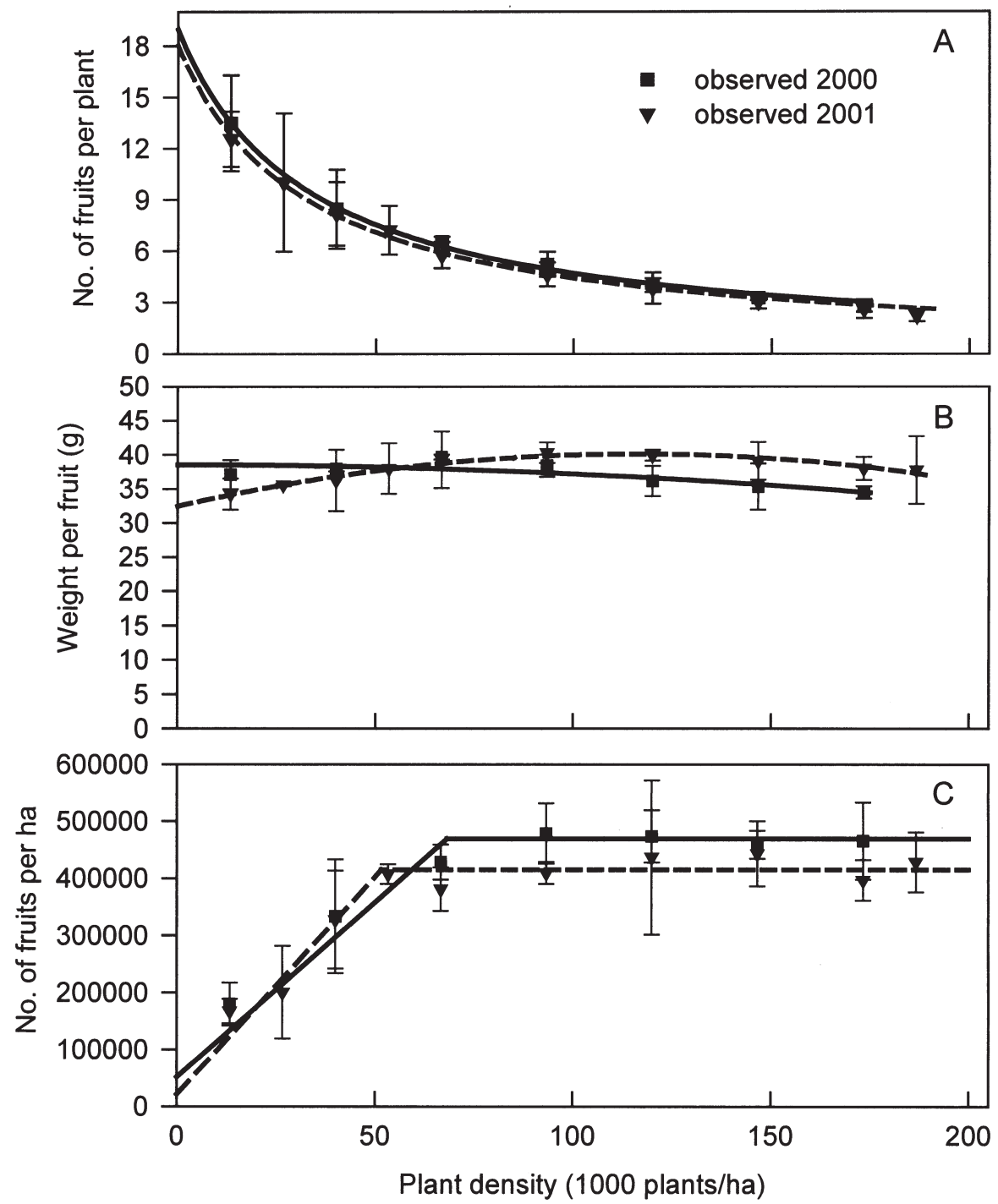

Fig. 3. Plant density effect on the components of yield of pimiento pepper. The lines are regression curves for 2000 (solid line) and 2001 (dashed line). Error bars represent \pm 1 standard deviation. (A) For the number of fruit per plant the regression curve is $\boldsymbol{y}=a /[1+(a \boldsymbol{x} / b)]$. In 2000, $a=19.0 \pm 0.6$, $b=624,194 \pm 22,456, r^{2}=0.99$. In 2001, $a=18.0 \pm 0.6, b=581,891 \pm 20.969, r^{2}=0.99$. (B) Fruit weight. In 2000, the regression curve is $\boldsymbol{y}=a+b \boldsymbol{x}^{2}$, with $a=38.54(P<0.001)$ and $b=-1.34 \times 10^{-10}$ $(P<0.05), r^{2}=0.60$. In 2001, the regression curve is $\boldsymbol{y}=a+b \boldsymbol{x}+c \boldsymbol{x}^{2}$, with $a=32.47(P<0.001), b$ $=0.000132(P<0.001), c=5.70 \times 10^{-10}(P<0.001), r^{2}=0.95$. $(\mathbf{C})$ Number of fruit per hectare. The linear plateau equation was used, $\boldsymbol{y}=a+b \boldsymbol{x}$ if $\boldsymbol{x}<c$ and $\boldsymbol{y}=a+b$ c if $\boldsymbol{x} \geq c$. In 2000, $a=51,827 \pm$ $29,662, b=6.12 \pm 0.75, c=68,169 \pm 6,464, r^{2}=0.96$. In 2001, $a=21,474 \pm 22,969, b=7.62 \pm 0.92$, $c=51,614 \pm 4,438, r^{2}=0.97$.

ear-plateau. The number of fruit per hectare increased with plant density up to 68,000 plants/ha in 2000, and up to 52,000 plants/ha in 2001(Fig. 2C).

Color. Fruit color was not affected by plant density (data not shown).

Relationship between intercepted PAR and yield. The percentage of intercepted PAR by the pepper canopy increased with the plant density. This increase was linear $\left(r^{2}=0.94 ; P\right.$ $<0.001)$ at the earliest measurement date but it was asymptotic at the latest measurement date (Fig. 4). Thus, the cumulative intercepted PAR increased with plant density at plant densities $<100,000$ plants/ha, but only slightly increased at higher densities (Fig. 4).

There was a linear relationship between the marketable yield and the intercepted PAR by the pepper canopy when the plant density was $\leq 93,333$ plants/ha $\left(r^{2}=0.88 ; P<0.001\right)$ (Fig. 5). No relationship between the yield and the intercepted PAR was found at higher densities $(P>0.05)$.

\section{Discussion}

Yield of marketable pimiento pepper 'Piquillo' increased as plant density increased from 13,333 to100,000 plants/ha because the number of fruit per hectare also increased with plant densities close to that threshold, while the weight per fruit was almost unaffected (2000) or increased with the plant density (2001). However, the relevant yield decrease found at higher plant densities in one of the years was due to the decrease in fruit weight. This indicates that plant density should not exceed 100,000 plants/ha. This yield decrease at high plant densities was not found in a previous study with paprika pepper in the same location (Cavero et al., 2001), even if higher plant densities were tested. In both works there was a similar decrease in fruit number per plant as plant density increased and a slight decrease in fruit weight as plant density increased, but in the case of paprika pepper there was a continuous increase in the number of fruit harvested per ha. In the case of paprika cultivars all the mature fruit are harvested independently of their size. However, the fruit of pimiento pepper 'Piquillo' must weigh $\geq 33 \mathrm{~g} /$ fruit to be marketable. Thus, in the case of this pepper cultivar, the decrease in fruit weight induced by the increased plant density limits the number of marketable fruit per ha and given that they are decreasing in size at high plant densities, a reduction in marketable yield could occur as in 2000 .

Similar effects of plant density on yield per plant and number of fruit per plant have been reported by other authors in bell pepper (Batal and Smittle, 1981; Jolliffe and Gaye, 1995; Locascio and Stall, 1994; Russo, 1991; Stoffella and Bryan, 1988), cayenne pepper (Decoteau and Graham, 1994), paprika pepper (Kahn et al., 1997), pepperoncini pepper (Motsenbocker, 1996), and tabasco pepper (Sundstrom et al., 1984). However, a similar stability or decrease in pepper yield per ha at high density has only been reported in Tabasco pepper in one of two experimental locations (Sundstrom et al., 1984), and there is no report of a similar slight decrease in fruit size at high density. This is probably because all these researchers did not test plant populations as high as were tested by Cavero et al. (2001) and in the present study, with the exception of Stoffella and Bryan (1988).

In bell pepper, Motsenbocker (1996) and Jolliffe and Gaye (1995) reported that leaf area per plant decreased while the leaf area index (LAI) increased as plant density of peppers increased. Cebula (1995) and Lorenzo and Castilla (1995) reported higher radiation interception because of higher LAI at higher plant densities, which resulted in higher biomass and pepper fruit yield. Similarly, the present study showed an increased radiation interception as plant density increased and, given the wide range of plant densities studied, revealed the asymptotic nature of the relationship between the intercepted PAR and the plant density. Our results indicated that the intercepted PAR increased with increases in plant density to about 100,000 plants/ha and that this increased interception of PAR resulted in increased yield.

The increase in yield as a consequence of increased plant density was only obtained in the first harvest date, which is consistent with the fact that the differences in the percentage of intercepted PAR between the different plant density treatments decreased along the season. Moreover, this effect was more important in 2001, probably because peppers were harvested 3 weeks earlier than in 2000. Thus, in 2001 a $50 \%$ increase in yield in the first harvest was observed between the 100,000 and 50,000 plants/ha, while this increase was only $25 \%$ in 2000. 

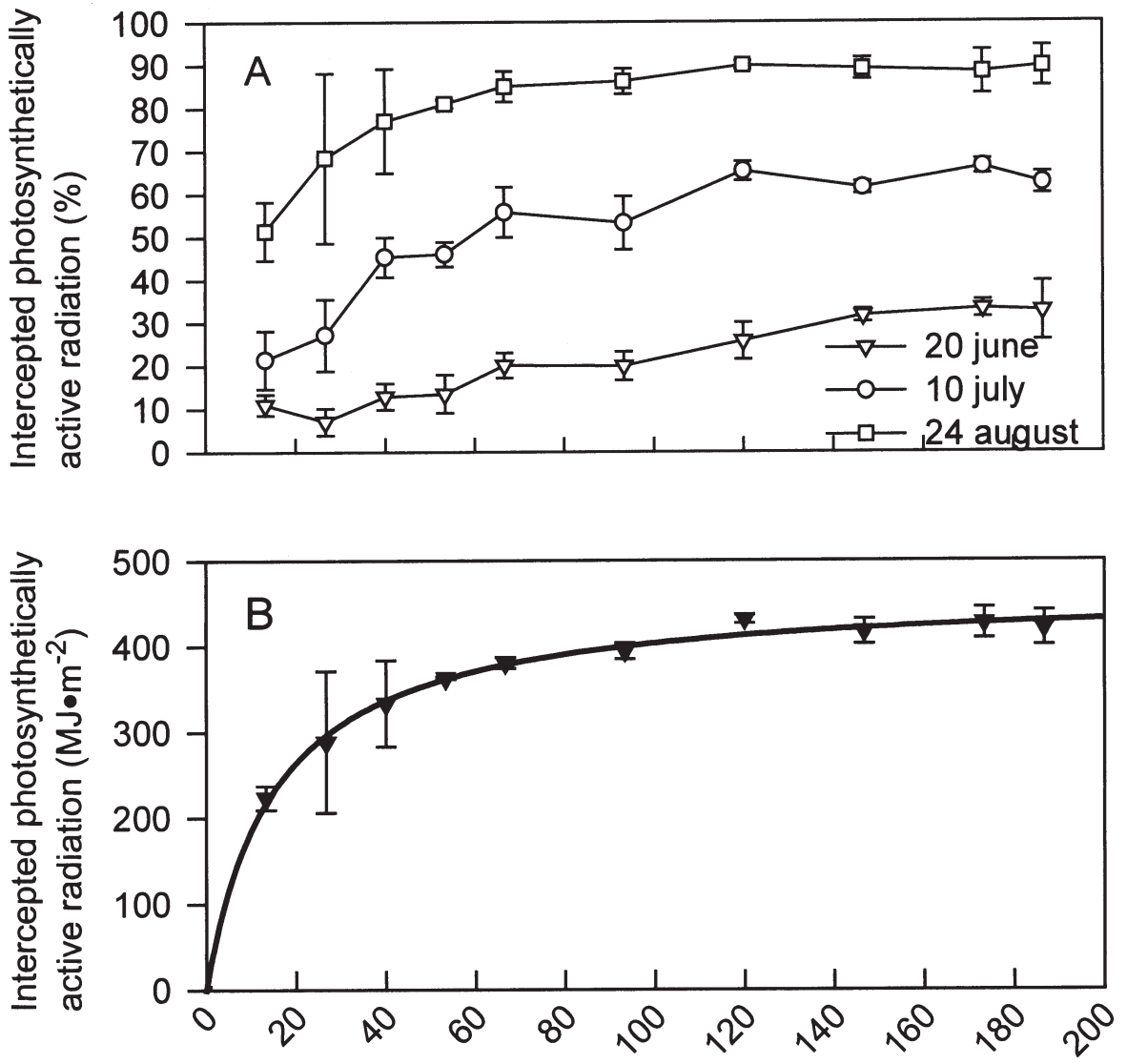

Plant density (1000 plants/ha)

Fig. 4. Plant density of pimiento pepper effect on (A) the percentage of intercepted photosynthetically active radiation (PAR) at different dates and (B) the cumulative intercepted PAR from mid June to the final harvest in 2001. Error bars represent \pm one standard deviation. In $\mathbf{B}$, the line is the regression curve $\boldsymbol{y}=a \boldsymbol{x} /[1+(a \boldsymbol{x} / b)]$, with $a=0.031 \pm 0.002, b=464.4 \pm 5.8, r^{2}=0.99$.

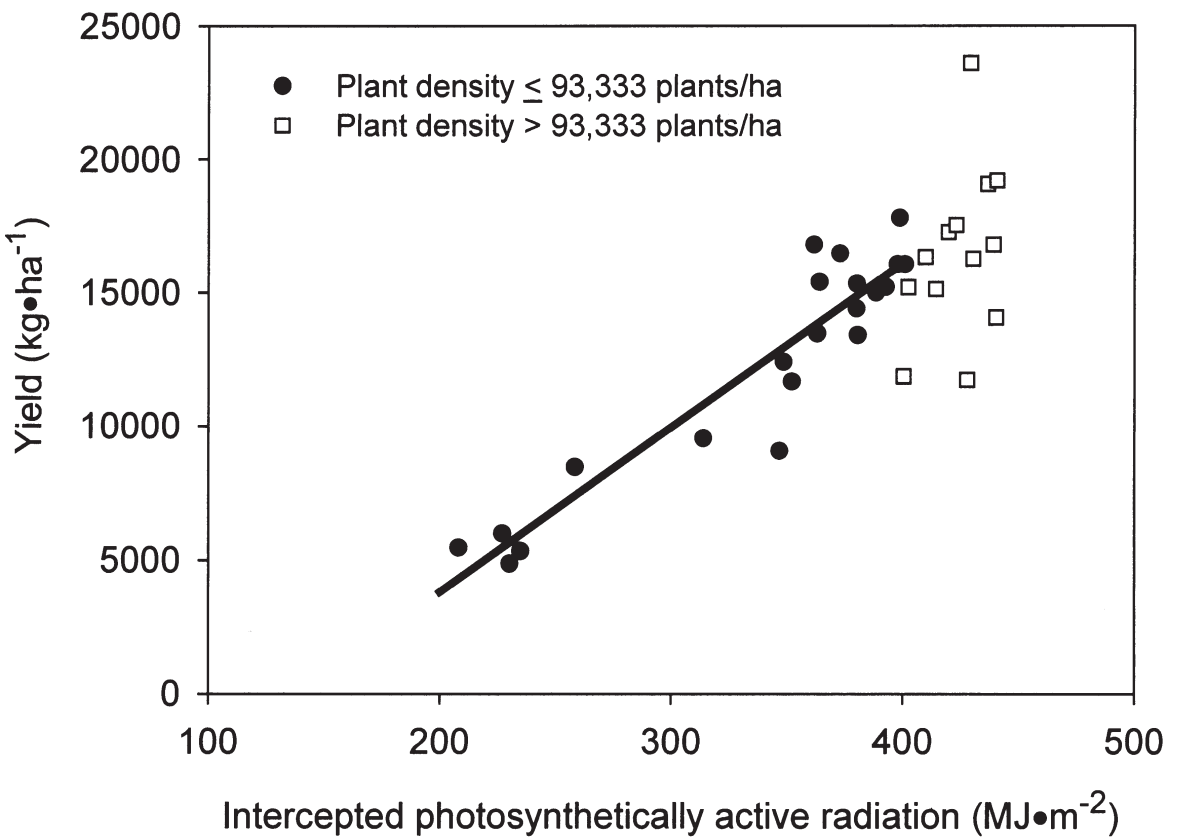

Fig. 5. Relationship between the intercepted photosynthetically active radiation from mid June to the final harvest and the marketable yield of pimiento pepper in 2001. The line represent the regression curve for plant density $\leq 93,333$ plants/ha, intercept $=-8,487 \pm 1,811$, slope $=61.46 \pm 5.27, r^{2}=0.88, P<$ 0.001 .
Direct seeding of pimiento peppers is a relatively new technique in Spain. The results indicate that when 'Piquillo' is grown with this technique, populations around 100,000 to 120,000 plants/ha are optimal in terms of yield, earliness and fruit size. Using these plant densities will also help avoid excessive use of seed for stand establishment.

\section{Literature Cited}

Batal, K.M. and D.A. Smittle. 1981. Response of bell pepper to irrigation, nitrogen and plant population. J. Amer. Soc. Hort. Sci. 106:259-262.

Cavero, J., R. Gil Ortega, and C. Zaragoza. 1996. Clear plastic mulch improved seedling emergence of direct-seeded pepper. HortScience 31:70-73.

Cavero, J., R. Gil Ortega, and M. Gutierrez. 2001. Plant density affects yield, yield components, and color of direct-seeded paprika pepper. HortScience 36:76-79.

Cebula, S. 1995. Optimization of plant and shoot spacing in greenhouse production of sweet pepper. Acta Hort. 412:321-329.

Cerrato, M.E. and A.M. Blackmer. 1990. Comparison of models for describing corn yield response to nitrogen fertilizer. Agron. J. 82:138-143.

Decoteau, D.R. and H.A.H. Graham. 1994. Plant spatial arrangement affects growth, yield, and pod distribution of cayenne peppers. HortScience 29:149-151.

Jolliffe, P.A. and M.M. Gaye. 1995. Dynamics of growth and yield component responses of bell peppers (Capsicum annиum L.) to row covers and population density. Scientia Hort. 62:153-164.

Kahn, B.A., J.R. Cooksey and J.E. Motes. 1997. Within-row spacing effects on traits of importance to mechanical harvest in paprika-type peppers. Scientia Hort. 69:31-39.

Locascio, S.J. and W.M. Stall. 1994. Bell pepperyield as influenced by plant spacing and row arrangement. J. Amer. Soc. Hort. Sci. 119:899-902.

Loomis, R.S. and D.J. Connor. 1992. Crop ecology: Productivity and management in agricultural systems. Cambridge Univ. Press, Cambridge, U.K.

Lorenzo, P. and N. Castilla. 1995. Bell pepper yield response to plant density and radiation in unheated plastic greenhouse. Acta Hort. 412:330-334.

McGuire, R. 1992. Reporting of objective color measurements. HortScience 27:1254-1255.

Meek, D.W., J.L. Hatfield, T.A. Howell, S.B. Idso, and R.J. Reginato. 1984. A generalized relationship between photosynthetically active radiation and solar radiation. Agron. J. 76:939-945.

Motsenbocker, C.E. 1996. In-row plant spacing affects growth and yield of pepperoncini pepper. HortScience 31:198-200.

Russo, V.M. 1991. Effects of fertilizer rate, application timing and plant spacing on yield and nutrient content of bell pepper. J. Plant Nutr. 14:1047-1056.

STATGRAPHICS. 1988. User's guide-system. STSC, Rockville, Md.

Stoffella,P.J. and H.H. Bryan. 1988. Plant population influences growth and yields of bell pepper. J. Amer. Soc. Hort. Sci. 113:835-839.

Sundstrom, F.J., C.H. Thomas, R.L. Edwards, and G.R. Baskin. 1984. Influence of N and plant spacing on mechanically harvested tabasco pepper. J. Amer. Soc. Hort. Sci. 109:642-645. 